This book is not a textbook but it provides enough information on an enormous range of topics to justify a place in the libraries of schools, hospitals, assessment centres, community units, and anywhere involved in special education. Its great strength is that it brings together information from a variety of disciplines in a most accessible format. I am filled with admiration for the author and editors, such interdisciplinary accord is rare!

MARY MCKAY Lecturer in child health

Common Problems in Pediatric Surgery. Jay L Grosfeld. (Pp 310; £43 hardback.) Mosby Year Book, 1991. ISBN 0-8151-3949-7.

The aims of this book are clearly defined in the preface and achieved with great success and brevity. Instead of providing yet another 'comprehensive' but dry text, here are 42 clinical topics, each 'tackled' by a different North American author.

The book is written for busy surgical registrars requiring a brief essay on the relevant aetiology and pathophysiology, but authoratitive guidelines on clinical presentation and management. The authors are well chosen for their clarity of style and their depth of experience. Each chapter finishes with a short list of references. Although most of the topics do present commonly in children's units, some, like choledochal cysts and achalasia, are rarities. The chapters on inguinal hernias are excellent and important. Topics such as trauma and vascular access are included.

This book is strongly recommended for all hospital libraries and any surgeons responsible for the care of children. Although primarily for surgeons in training, experienced surgeons will find this a most useful book, particularly when preparing lectures.

DAVID P DRAKE Consultant paediatric surgeon

The Evidence of Children: The Law and the Psychology. J R Spencer, R Flin. (Pp 362; $£ 19.50$ paperback.) Blackstone Press Ltd, 1990. ISBN 1-85431-040-2.

The issue of the evidence of children, the law, and the psychology is an alive issue currently. With proposals for changes in practice using videotapes of evidence, as recommended by Pigot, there is a major need for an authoritative text on the examination of these issues. Both authors, J R Spencer and R Flin, have played a key part in bringing these issues to professional and public attention. They have provided an equally authoritative text which gives an excellent outline of both the English and Scottish legal systems, as well as the concept of evidence, the requirement for a detailed account of the accusatorial system within which evidence occurs, and a detailed account of the rule against hearsay.

The authors then give a full account of the issues raised when videotapes are used, for example, notions about the corroboration necessary for evidence, and the role of expert assistance. They are critical of the rules of evidence, and provide a detailed review of the psychological evidence as given by child witnesses. They then describe the proposals and the ways in which children give evidence in other contexts.
Sadly, although the case has been argued by Spencer and Flin, both in this book and in many other contexts, there is still a tremendous resistance to ensuring that the evidence given by children will have the fullest opportunity to be presented in court. Unfortunately the battle to ensure that the child's voice is heard remains to be won, and although it would appear that videotapes of children's evidence may be admissible, it also appears that children may still have to be cross questioned on that account at the time of trial rather than soon after they have given their evidence initially. The battle between the child's best interests and a defendant's best interests is a difficult one to win. Although the law has not changed entirely in children's interests, the evidence is present in this book to convince some future legislature about the need to do so.

\section{ARNON BENTOVIM} Consultant psychiatrist

Play in Childhood. By Margaret Lowenfeld. (Pp 246; £28 hardback.) Blackwell Scientific Publications, 1991. ISBN 0-901260-84-3.

What a pleasure to reread Play in Childhood now published in the series Classics in Developmental Medicine. I began anxiously wondering how relevant the book would be. It was first published in 1935 but her holistic approach and emphasis on the children themselves and practical ways to facilitate play has much to offer in the 1990s.

The book describes the observation of play and through a series of chapters describes play as bodily activity, play as repetition of experience, as demonstration of phantasy, realisation of environment, and preparation for life. There are chapters on group games, the comic element of play, and children who cannot play.

The chapter on observation of play is practical, describing ways of encouraging play with children, and the material of play. The chapter on play as preparation for life reads of a different childhood and expectations of the roles of boys and girls and reminds us of changed perceptions about gender, but other chapters are full of practical suggestions and lively records of children's conversations in play.

There are practical descriptions of the objects used and the function of her 'world' material with examples of how children use this material. The book is clearly and coherently written empowering the reader to want to use her ideas unlike many other books on play of that period that deskill the reader with a less pragmatic approach. What clearly shines through this book is Margaret Lowenfeld's capacity to put children first and hear what they had to say.

Finally as Lowenfeld emphasised the sensory experiences of play, may I thank the publishers for the thickness and texture of the pages in the book-a pleasure to touch for the adult/child.

ANN CATTANACH Dramatherapist-play therapist

Operative Pediatric Orthopedics. Edited by S T Canale and J H Beaty. (Pp 1159; £116.50 hardback.) Mosby Year Book, 1991. ISBN 0-8016-0392-7.

New books on the techniques and details of operative orthopaedics are currently fashionable. This book, edited by Drs Canale and Beaty is, however, from a stable from which textbooks of operative orthopaedics have come for more than a generation. The Campbel Clinic has for many years been the authority to which many orthopaedic surgeons refer before operations and their Campbell's Operative Orthopedics remains a classic. This book considers the problems of operative orthopaedic surgery in children and is managed in the same format. Multiple authors deal with the various orthopaedic problems in children, although Dr Canale and Dr Beaty cover nine of the 19 chapters. The valuable opening chapter deals with the common orthopaedic realignment procedures used to correct rotatary and angular deformity. Although much of this chapter is conventional, the author's method of identifying the amount of correction and the size of the wedge to be removed is not only original but very useful. In considering the general aspects of children's orthopaedics the procedure has been followed as in Campbell's Operative Orthopedics of detailing individual procedures, their indications, and prerequisite without being severely critical of the indications and merits. The reader is not always left with the definite view of the author's management of a particular individual case. Each section of the book is well provided with references to allow the reader to research widely around the subject. Having made this criticism it must be accepted that this is a book on operative orthopaedics and space cannot be found for all aspects of diagnosis. It does have a great deal to commend it and is undoubtedly a great contribution to the enlarging literature not only for its general quality but also to the extent to which it covers all aspects of children's orthopaedics. I am sure it will be of great value to the orthopaedic resident and the practising orthopaedic surgeon for its completeness not only of its operative surgery but also its bibliography. It could act as a source of reference for medical students and interns but its detail may be beyond them. There is no doubt, however, of the value of this text which is currently concise at just over 1100 pages and one volume. Further editions may result in a multivolumed text.

\section{ANTHONY CATTERALL} Consultant orthopaedic surgeon

Common Problems in Pediatric Urology. E Gonzales and D Roth. (Pp 485; £50 hardback.) Mosby Year Book, 1991. ISBN 0-81513616-1.

This book covers a broad range of paediatric urological problems, which are presented in a stimulating manner. Each chapter commences with a short case presentation and the management is subsequently discussed by a recognised expert. Most of the chapters are of a high standard, but there are a few that lack detail.

The clinical cases have been chosen well and include most of the clinical problems facing a practising full time or maximum part time paediatric urologist.

This book is attractive as it is comprehensive, relatively short, and easy to read. It is very clinically orientated and yet provides an excellent up to date overview. 